\title{
A Leitura Digital no Contexto Escolar: Desafios e Possibilidades
}

\author{
Digital Reading in The School Context: Challenges and \\ Possibilities
}

Marciele Scholl1; ${ }^{1}$ Silvani Lopes Lima²

\section{RESUMO}

Este trabalho apresenta os resultados de uma pesquisa realizada com estudantes das séries finais do ensino fundamental de uma escola do campo no interior do Rio Grande do Sul, na qual buscamos empregar metodologias que permitissem verificar os desafios e as possibilidades da leitura digital no contexto escolar. Partindo de fundamentação teórica relevante (CHARTIER, 1999, 2003; COLOMER, 2007; ROJO, 1998; SOBRAL, 2002; TERRA, 2015), inicialmente, foi aplicado um questionário a fim de conhecer as preferências de leitura dos alunos. Em seguida, foram realizadas práticas de leitura em meio impresso e digital para avaliar a recepção dos alunos à leitura literária nas diferentes plataformas. A partir dos dados obtidos, constatamos que a leitura digital é uma importante ferramenta a ser utilizada pelos educadores uma vez que permite o acesso instantâneo e em qualquer lugar ao texto. Também que esse tipo de leitura não minimiza a importância do livro impresso, pois, mesmo tendo acesso à internet, muitos educandos demonstram ter preferência pelo contato com o papel durante a leitura e mesmo aqueles que gostam da leitura em meio digital não descartam a prática da leitura em meio impresso.

Palavras-chave: Práticas de leitura juvenil. Leitura literária. Plataformas de leitura. Texto impresso. Texto digital.

\begin{abstract}
This paper presents the results of a research carried out with the final grades of elementary education students' in a country school situated in the state of Rio Grande do Sul, in which we applied methodologies that enable us to verify the challenges and possibilities of digital reading in the school context. Initially, a questionnaire was applied in order to cognize the information about the students' reading preferences, grounded on relevant theoretical foundation (CHARTIER, 1999, 2003; COLOMER, 2007; ROJO, 1998; SOBRAL, 2002; TERRA, 2015). Then, reading practices in printed and digital media were carried out in order to evaluate students' reception to literary reading in the distinct platforms. From the data obtained, we could verify that digital reading is an important tool to be used by educators since it allows immediate and anywhere access to the text. As well, this type of reading does not minimize the printed book relevance, once, even having access to the internet, many students show preference for direct contact with paper during reading and even those who enjoy digital reading do not discard the printed reading.
\end{abstract}

Keywords: Youth reading practices, Literary reading. Reading platforms, Printed text. Digital text.

\footnotetext{
1 Secretaria da Educação do Rio Grande do Sul, Ibirubá/RS - Brasil.

2 IFRS - Instituto Federal de Educação, Ciência e Tecnologia do Rio Grande do Sul, Ibirubá/RS - Brasil.
} 


\section{INTRODUÇÃO}

Neste trabalho, com enfoque em estudos relacionados à leitura, especialmente no que tange aos novos desafios no ensino da leitura e formação de leitores, buscamos verificar possibilidades de aliar a leitura digital como instrumento de estímulo ao ato de ler.

Com o advento da internet, a tecnologia chegou paulatinamente às escolas, tornando-se um importante recurso a ser utilizado. Como profissionais da área de Letras, percebemos que o livro impresso vem perdendo espaço para aplicativos de leitura que podem ser utilizados em celulares, tablets ou notebooks. Nesse sentido, utilizar esses recursos nas aulas de ensino de língua e literatura torna-se uma alternativa bastante plausível para obter sucesso na aquisição e prática da leitura. Sobre o uso da internet, Sobral destaca que esta

combina perfeitamente com os novos rumos da educação por ser adequada à nova relação aluno-professor, centrada no aluno e na ação deste como sujeito, e que requer do professor que se torne um companheiro, mais experiente, na jornada do conhecimento.

Além de permitir que o professor também aprenda com o aluno, a Internet facilita a motivação deste, promovendo o trabalho em grupo e a troca dinâmica de informações com os colegas. (SOBRAL, 2002, p.15)

Se há novos recursos a serem explorados para o acesso e a prática da leitura, é preciso que seu uso seja estimulado e não rejeitado. Não será através do combate à internet em sala de aula que os estudantes farão bom uso dela, mas sim a partir de práticas interessantes, que possibilitem o uso consciente das tecnologias durante as aulas. É preciso transformá-las em instrumento de conhecimento - e conhecimento é conquistado não só a partir das leituras propostas no contexto escolar (e restritamente em meio impresso), mas também das leituras do mundo.

Então, se a leitura no papel não atrai o aluno, por que não utilizar as ferramentas digitais que despertam a sua curiosidade e o seu interesse para esse fim? Torna-se mais interessante o uso da tecnologia ou o abandono da leitura? O professor deve rejeitar ou aliar-se à tecnologia como ferramenta de estímulo à leitura? Essas são algumas questões que nos instigaram no decorrer desta pesquisa.

Partimos da concepção de que ler é adquirir conhecimento, viajar e conhecer novos lugares sem se mover, é perceber o mundo a partir de diferentes olhares. Nesse sentido, o importante é que os educandos desfrutem de tal experiência independente da forma como a leitura é oferecida, se no livro impresso ou em um aplicativo digital, o que realmente interessa é que o gosto pela leitura seja despertado desde cedo.

No entanto, uma das grandes resistências em relação à leitura digital é não saber como proceder no momento de trabalhar com plataformas digitais e com acesso à internet, teme-se que o aluno possa ler materiais impróprios ou não condizentes com o momento da aula. Temerosos, muitos professores impõem apenas leituras em material impresso, impossibilitando que seus estudantes possam alargar seus horizontes de leitura.

Assim, estimular a leitura com o auxílio das novas tecnologias é fazer com que o ato de ler não se acabe. Ações como ir à biblioteca ou comprar um livro, principalmente se for considerado o seu custo relativamente alto, demandam tempo e poder aquisitivo, exigências que podem desestimular a prática 
da leitura. Se o livro impresso vem perdendo seu espaço isso não quer dizer que o estudante não esteja lendo. Pelo contrário, com o advento da internet, a leitura torna-se mais expansiva, uma vez que pode ser acessada de qualquer local e a qualquer momento, além de não gerar despesas financeiras.

Dessa forma, a leitura digital permite que o estudante tenha acesso facilitado aos mais variados materiais, o que pode estimulá-lo a ler mais e possibilitar a aquisição de novos conhecimentos com o auxílio das tecnologias. Levando isso em consideração, torna-se necessário que os educadores planejem suas aulas valendo-se dos recursos da era digital disponíveis também no contexto escolar. Nesse sentido, esta pesquisa teve como objetivo a análise da eficácia das práticas de leitura digital como instrumento de incentivo ao gosto pela leitura entre os educandos.

O estudo proposto, partindo de fundamentação teórica, consistiu em uma pesquisa de campo com duas turmas escolhidas para ser o objeto de investigação - 70 e 90 ano do ensino fundamental de uma escola do campo de um município do interior do estado do Rio Grande do Sul.

Definido o público-alvo da pesquisa, foi organizada uma reunião com estes educandos e seus respectivos responsáveis a fim de explicar a pesquisa de campo e esclarecer dúvidas que ainda pudessem, eventualmente, surgir. Com as dúvidas esclarecidas e as devidas autorizações entregues, foram iniciadas as seguintes atividades: aplicação de questionário (APÊNDICE A) sobre as preferências de leitura destes educandos; leitura de uma obra literária impressa; registro escrito dessa primeira experiência; apresentação do livro digital e leitura neste formato; registro escrito da segunda experiência; e, para finalizar, realização da leitura de um livro pelos educandos, impresso ou digital, à sua livre escolha. Depois da leitura, foi feita uma roda de conversa a fim de possibilitar que os discentes relatassem o que sentiram e que tipo de leitura mais Ihe chamou a atenção.

Com a conclusão das atividades previstas para a pesquisa de campo, os dados foram reunidos, compilados e analisados em busca de respostas concretas para a problemática em investigação. Com os dados levantados, foi realizado o registro da pesquisa, cuja fundamentação teórica, abordagem metodológica, resultados coletados e discussões serão apresentados nas próximas seções.

\section{O PROCESSO DE LEITURA: AQUISIÇÃO E AMPLIAÇÃO DE PRÁTICAS DE LEITURA}

Ler é um ato de coragem e de rebeldia, pois a maioria dos textos propõem algum desafio ao leitor. Ao praticar a leitura, ora estamos a par dos acontecimentos ao nosso redor, ora nos distraímos em busca de novos espaços e conhecimentos. $\mathrm{O}$ ato de ler - independente se um jornal, uma revista ou um livro, se em meio impresso ou digital - sempre trará algo de novo, pois é um exercício mental e permite que o leitor tenha argumentos para discutir as questões que ele julgar importantes. Nesse viés, Anne Marie Chartier (2003, p. 46-47) diz que "ler antes de toda consideração, suportes e conteúdos deve ser julgado como um gesto incondicionalmente positivo. Portanto, é necessário fazer tudo para 'salvar a leitura'."

A introdução ao mundo da leitura deveria acontecer em casa, com o auxílio dos pais. Entretanto, nem sempre é isso que ocorre. O mundo está cada vez mais acelerado, muitos pais possuem dupla jornada de trabalho e, desse modo, torna-se mais cômodo ligar a televisão, emprestar o tablete ou o celular para distrair uma criança do que sentar para ler com ela. Nesse contexto, a escola passa a ter maior relevância no estímulo à leitura, pois, na maioria dos casos, é nela que o educando terá seus 
primeiros contatos com a leitura. Porém, se o ato de ler por prazer é comumente estimulado entre os pequenos, por que os educadores mudam sua atitude quando os educandos chegam aos anos finais do ensino fundamental? Ora, a leitura deve ser vista como algo agradável, não imposto. E o conhecimento precisa ser uma consequência de algo que foi realizado pelo estudante e que fez sentido para sua vivência.

A leitura transforma a vida e o mundo. Ler apenas por obrigação faz com que dois dos sentidos da educação se percam: a reflexão e a criticidade. Terra (2015) chama a atenção para a importância da leitura neste universo digital, pois não há nada mais contextualizado à leitura do mundo do que o uso do livro digital, o qual oferece acesso instantâneo aos mais diversos e ricos materiais. No entanto, é preciso tomar cuidado, pois nem tudo que está disponível possui qualidade. Ainda assim, se bem classificados, os materiais disponibilizados digitalmente podem trazer inúmeras contribuições ao universo escolar.

\subsection{0 acesso à leitura e o avanço da tecnologia}

Há não muito tempo, a única possibilidade de leitura era a impressa. Os livros possuíam alto custo para a maioria da população e eram relativamente de difícil acesso, restringindo-se, muitas vezes, à escola. Com o advento da tecnologia, em especial com a disseminação da internet, as barreiras de acesso e o valor do livro foram diminuindo. Se considerarmos a história do livro impresso, percebese a enorme evolução por que ele passou. Nos primórdios, ele era escrito não com caneta, mas com uma pena com tinta e por religiosos, que, até então, eram a parte da sociedade que tinha acesso à leitura. Muito tempo depois, Gutenberg, com a invenção da imprensa, possibilitou a divulgação de obras, porém, seu acesso se dava somente para pessoas que possuíam alto poder aquisitivo. A partir de meados do século XX, com formas de impressão mais modernas, o livro torna-se mais acessível à maior parte da população. No entanto, a aquisição do livro ainda era por aquelas pessoas classificadas como leitoras assíduas; às demais, o acesso era através de bibliotecas públicas ou das escolas e, normalmente, com alguma cobrança. No início do século XXI, com a propagação de menor custo de acesso à internet, qualquer pessoa que disponha desse recurso, através de um computador, celular ou tablet, pode acessar algum livro digital. Para Belo (2007), não são apenas os formatos do livro que mudam, mas também a forma que o leitor lê, pois este pode, com um clique, ir para a página que desejar ou até mesmo trocar de leitura se assim o quiser. Essa evolução tecnológica não apenas facilita o acesso ao livro, mas permite que o leitor escolha o que, como e onde quer ler.

Com a digitalização crescente de textos e imagens, artigos, jornais, revistas ou livros inteiros, o que anteriormente apenas podia ser lido na forma impressa pode agora, complementarmente ou em alternativa, ser lido numa tela de computador, pela Internet, em um CD-ROM, ou em outro aparelho que permita a leitura em suporte digital. Com efeito, se for lido numa tela, o texto que o leitor estiver lendo será inevitavelmente lido de uma outra maneira: desaparecem os gestos e as sensações do leitor associados ao manuseio do livro impresso e muda a sequência da leitura. Em vez de seguirem uma ordem linear, de uma página inicial a uma página final, os capítulos de um livro digital estão relacionados entre si segundo outra lógica, permitindo ao leitor entrar nele de um ponto qualquer a partir do índice. O leitor pode passar de um capítulo do texto para o outro por meio de um simples clique de "mouse", e de um texto para outros textos (e imagens e sons) sem sair da mesma tela. (BELO, 2007, p.5-6). 
Dentro de um contexto em que novas informações surgem a todo momento e o ser humano precisa estar constantemente atualizado, utilizar a tecnologia a favor do ensino não é apenas pesquisar um assunto, copiar, imprimir e distribuir entre os educandos para que eles respondam um questionário. Transformar as novas tecnologias em instrumentos de ensino é permitir que elas entrem na sala de aula como fonte de pesquisa e reflexão acerca da realidade. É possibilitar que os estudantes viajem sem se mover, que conheçam novos locais e diferentes culturas com alguns cliques. Essas ações são formas de ler o mundo, a vida, o ser humano. Nesse viés, Freire diz que

Ler é uma operação inteligente, difícil, exigente, mas gratificante. Ninguém lê ou estuda autenticamente se não se assume, diante do texto ou do objeto da curiosidade a forma crítica de ser ou de estar sendo sujeito da curiosidade, sujeito da leitura, sujeito do processo de conhecer em que se acha. Ler é procurar, buscar ou criar a compreensão do lido; daí, entre outros pontos fundamentais, a importância do ensino correto da leitura e da escrita. É que ensinar a ler é engajar-se numa experiência criativa em torno da compreensão. Da compreensão e da comunicação. E a experiência da compreensão será tão mais profunda quanto sejamos nela capazes de associar, jamais dicotomizar, os conceitos emergentes na experiência escolar aos que resultam do mundo da cotidianidade. (FREIRE, 1997, p. 20).

Ainda assim, o fato de os educadores ainda resistirem às novas ferramentas de leitura deve-se, muito provavelmente, ao receio de não saber como manuseá-las. Não podemos esquecer que grande parte dos docentes que estão em sala de aula foram formados dentro de um contexto pré-digital, onde a informação demorava a chegar, as fontes de pesquisa eram impressas e os estudantes tinham como tarefa decodificar símbolos. Para Rojo (1998, p. 2), "ler era visto - de forma simplista - apenas como um processo perceptual e associativo de decodificação de grafemas (escrita) em fonemas (fala), para se acessar o significado da linguagem do texto."

No entanto, o ato de ler é algo dinâmico, requer interação entre o leitor, o texto e o mundo. A leitura é um instrumento de comunicação que pode ora auxiliar no processo de interação com o mundo, ora na introspecção do ser humano em relação à realidade que o cerca. Assim como a leitura pode ser uma fuga, ela pode resgatar o sujeito, trazendo-o à realidade, fazendo-o refletir e transformar o mundo que o cerca.

\subsection{Livro digital x livro em papel: desafios e possibilidades}

Com o avanço tecnológico e o acesso instantâneo aos materiais de leitura, é notável que também ocorra mudanças na cultura e no pensamento dos educandos. Nesse sentido, é importante verificar se essas mudanças são favoráveis ou não ao contexto escolar.

Ao que tudo indica, fazer uso das novas tecnologias, em especial do livro digital, é uma forma de tornar mais atrativa a aula e aproximar o estudante da realidade em que está inserido, afinal, ele já usa celulares, tablets e computadores, dominando-os melhor que seus professores. De acordo com Soares, estas mudanças chegaram para auxiliar, todavia usá-las em benefício da aprendizagem é uma escolha do educador.

É que estamos vivendo, hoje, a introdução, na sociedade, de novas e incipientes modalidades de práticas sociais de leitura e de escrita, propiciadas pelas recentes tecnologias de comunicação eletrônica - o computador, a rede (a web), a Internet. É, assim, um momento privilegiado para, na ocasião mesma em que essas novas práticas de leitura e de escrita estão sendo introduzidas, captar o estado ou condição que 
estão instituindo: um momento privilegiado para identificar se as práticas de leitura e de escrita digitais, o letramento na cibercultura, conduzem a um estado ou condição diferente daquele a que conduzem as práticas de leitura e de escrita quirográficas e tipográficas, o letramento na cultura do papel. (SOARES, 2002, p. 146).

Compreender o porquê de o livro impresso estar perdendo espaço para celulares ou computadores é indispensável para entender os desejos dos estudantes e verificar o que esperam das práticas pedagógicas de seus professores.

Outro aspecto a ser considerado é de que livros impressos a escola dispõe. São poucas as escolas que possuem obras literárias atualizadas, com assuntos que despertem o interesse dos educandos. Tradicionalmente, obras consagradas da literatura brasileira e da universal eram cobradas na escola. Os exemplares eram poucos, velhos e malcuidados devido à precariedade das bibliotecas escolares. Normalmente, com uma linguagem clássica, mais formal e difícil de ser compreendida, as obras canônicas não são tão bem recebidas por crianças e jovens, ou pelo menos não sem antes haver uma identificação do leitor com o texto, e isso ocorre geralmente através de textos mais próximos do jovem, geralmente obras contemporâneas e que tratam de temas do universo juvenil. Nesse sentido, as obras canônicas não têm sido eficazes no processo de estímulo à leitura, pois exigem mais maturidade e esforço dos jovens leitores. Suas preferências se voltam para obras que abordam temas do cotidiano, fazendo com que os discentes se identifiquem com esses textos.

O mercado, por sua vez, constata que há público e investe neste tipo de livro. Aliado a este novo contexto, com o fortalecimento do acesso à internet, há uma forte investida em livros digitais ou ebooks. De acordo com Chartier (1999), é através dessa evolução que o livro de papel sofre que a leitura digital se insere no contexto escolar. Em alguns cliques, o educando pode viajar pelo livro digital e, ao mesmo tempo, analisar a sua versão para o cinema e produzir um novo conhecimento. A rapidez com que essas ações se dão é tamanha que os educadores, muitas vezes, não conseguem acompanhar.

Se abrem possibilidades novas e imensas, a representação eletrônica dos textos modifica totalmente a sua condição: ela substitui a materialidade do livro pela imaterialidade de textos sem lugar específico; às relações de contiguidade estabelecidas no objeto impresso ela opõe a livre composição de fragmentos indefinidamente manipuláveis; à captura imediata da totalidade da obra, torna visível pelo objeto que a contém, ela faz suceder a navegação de longo curso entre arquipélagos textuais sem margens nem limites. Essas novas mutações comandam, inevitavelmente, imperativamente, novas maneiras de ler, novas relações com a escrita, novas técnicas intelectuais. (CHARTIER, 1999, p.100-101).

Entretanto dizer que a rapidez e a evolução tecnológica são as responsáveis por práticas de leitura descontextualizadas é uma forma de isentar o educador de suas responsabilidades profissionais. Cabe ao docente se atualizar e procurar despertar o interesse de seus educandos. Estimulá-los a desvendar o mundo da leitura e, diante do contexto atual, valer-se de obras digitais é uma boa forma de instigálos.

A leitura é uma das atividades mais ricas que pode ser desenvolvida em sala de aula. Ela vai além do repasse de informações. $O$ ato de ler é vital para a construção do conhecimento. Permite que o leitor não apenas conheça realidades diferentes, mas que interaja com elas e reflita acerca de sua própria realidade. O poder da leitura aliado à reflexão possibilita grandes transformações na vida e na sociedade na qual o indivíduo está inserido. 
Portanto, se a escola tem como objetivo participar da formação de sujeitos reflexivos, conscientes de seu papel na sociedade, cabe a ela oportunizar novas formas de leitura. Até porque a inserção ao mundo virtual, se feita adequadamente, não será sinônimo de alienação. Pelo contrário, pode ser a transformação de sujeitos desmotivados em sujeitos mais dedicados, próximos da escola, informados e contextualizados, dinamizando o ambiente escolar. Soares destaca, nesse sentido, que

A tela como espaço de escrita e de leitura traz não apenas novas formas de acesso à informação, mas também novos processos cognitivos, novas formas de conhecimento, novas maneiras de ler e de escrever, enfim, um novo letramento, isto é, um novo estado ou condição para aqueles que exercem práticas de escrita e de leitura na tela. (SOARES, 2002, p. 152).

\section{PERCURSO METODOLÓGICO}

O objeto deste estudo surgiu por meio de um projeto de leitura realizado na escola em que uma das pesquisadoras atua como professora de Língua Portuguesa. Com o título "Ler: embarque nesta viagem", o projeto visava um maior envolvimento dos estudantes durante a parada para a leitura com o intuito de estimulá-los a ler cada vez mais.

A atividade consistia em envolver os alunos já no início do processo. Isto é, antes de iniciar o projeto, os estudantes confeccionaram caixas para que cada turma pudesse transportar seus materiais de leitura, inclusive a outros setores da escola (secretaria, direção, refeitório, etc.). A eles também ficou a responsabilidade de fazer a seleção dos materiais de leitura para cada caixa e de escolher uma atividade de sensibilização e incentivo àquele momento em que toda escola para a fim de destinar trinta minutos da manhã para realizar alguma leitura de fruição.

Inicialmente, o projeto havia sido organizado para apenas uma parada mensal durante os meses do ano letivo de dois mil e dezesseis. Constatado o envolvimento dos estudantes, a atividade deixou de ser mensal passando a ser quinzenal, seguindo um calendário para a organização das turmas. Dessa forma, a atividade foi organizada de acordo com as seguintes etapas:

a) o grupo responsável pela semana, de acordo com o calendário, deveria trazer, previamente, o material de sensibilização e decidir qual texto seria utilizado e como a proposta seria desenvolvida nas turmas;

b) a turma deveria ser organizada em grupos para realizar a atividade de sensibilização, entrega e recolhimento das caixas de leituras;

c) posteriormente, os estudantes deveriam se dirigir à biblioteca para realizar a escolha dos materiais que iriam para as caixas.

Além do material das caixas, os estudantes teriam a liberdade de trazer de casa materiais de leitura, inclusive, se preferissem, leituras digitais por meio de celular, tablet ou notebook. Chegado o dia da parada da leitura, a turma entraria em cada uma das salas da escola iniciando aquele momento de leitura.

Já no primeiro dia do projeto, nossa curiosidade ficou aguçada em relação ao interesse dos alunos pelas leituras digitais. No entanto, não demos tanta importância por se tratar de um novo projeto e permitir, principalmente, o celular em sala de aula, uma conquista importante para os alunos já que 
o uso do celular é proibido devido à lei estadual no 12.884/2008 enviada às instituições de ensino do estado do Rio Grande do Sul.

Porém, os alunos começaram a trazer previamente textos digitais, de modo a assegurar que na parada da leitura pudessem desfrutar de textos oriundos da internet. Como a preferência dos educandos por leitura de textos digitais ficou evidente, isso passou a ser o objeto desta pesquisa.

Após aprovação do comitê de ética do Instituto Federal de Educação, Ciência e Tecnologia do Rio Grande do Sul - IFRS (CAAE: 58003416.0.0000.8024), uma vez que se relacionou com trabalho de conclusão de curso de especialização ofertado pela instituição, a pesquisa de campo foi desenvolvida a partir de meados do mês de agosto de dois mil e dezesseis. As turmas de 70 e 90 foram selecionadas para o estudo por terem demonstrado maior interesse em relação à leitura em versão digital. Dos 27 alunos das duas turmas convidadas para a pesquisa, 20 aceitaram responder ao questionário e realizar atividades de leitura. Daquele número inicial de estudantes, 3 haviam sido transferidos da escola e 4 optaram por não participar da pesquisa.

\section{EXPERIÊNCIAS E CAMINHOS DE LEITURA}

Conforme já mencionado na seção introdutória deste artigo, inicialmente foi aplicado um questionário (APÊNDICE A) a fim de verificar as preferências de leitura dos estudantes e os meios de acesso a estes materiais. Deste, as questões 1 a 4 relacionavam-se, respectivamente, com idade, gostar ou não de ler e porque, e acesso à internet. A faixa etária dos alunos pesquisados variou de 12 a 16 anos. Das turmas pesquisadas, apenas 2 estudantes responderam que não gostavam de ler e que, apesar de possuírem acesso à internet, preferiam acessá-la para jogar. Enquanto que apenas um dos entrevistados não tinha como acessar a internet, exceto na escola. Nas questões 5 e 6, referentes à preferências e tipos de leituras, os estudantes responderam de forma bem eclética, pois suas leituras variavam de livro a revistas e jornais, de histórias de aventura a terror ou comédias, entre outros.

A partir da questão 7, a pesquisa foi direcionada ao campo da leitura digital. Dos educandos pesquisados, apenas 3 não haviam lido um livro em versão digital. Sendo que entre os que afirmaram já ter lido pelo menos um livro digital apenas 3 alunos não tinham gostado da experiência.

A questão 9 indagava sobre a preferência entre livro em papel e livro digital. Nesse item, as respostas foram bem divididas (exatamente $50 \%$ dos educandos para cada opção). Para melhor compreender tais respostas, foram consideradas as faixas etárias dos discentes envolvidos na proposta. As respostas (6 respostas) dos educandos pesquisados entre 12 e 13 anos optou pela versão digital do livro, enquanto que aqueles entre 14 a 16 anos (também 6 respostas) marcaram o livro em papel como preferido.

A última pergunta estava relacionada à possibilidade de ler mais com o advento da versão digital dos livros. Nesse item, apenas 4 estudantes optaram pelo "não" como resposta. Destes alunos, 2 já haviam manifestado não gostar de ler e os outros 2 consideravam-se leitores assíduos. Independente de optar pela versão em papel ou digital, leriam o livro que lhes despertasse interesse e não em virtude do suporte de leitura.

Posteriormente, foi proposto um momento de leitura de livros na versão digital, uma vez que a leitura de livros em papel era uma prática constante nestas turmas. Passada uma semana, período para as 
turmas concluírem suas leituras, os estudantes foram incentivados a relatarem a experiência, que era nova para 3 deles. Nessa roda de conversa, três pontos foram levantados:

a) como havia sido a experiência;

b) aspectos positivos; e

c) aspectos negativos.

Durante as conversas, ambas as turmas demonstraram ter gostado da leitura em versão digital, consideraram uma atividade bem produtiva e com mais variedade de obras para escolherem. As duas turmas apontaram que neste formato de leitura não necessitava de tanto cuidado com o livro, pois neste formato ele não estragava, não sujava e foi possível ler sem aquela tensão de que poderiam ser cobrados se a obra não voltasse da forma como havia sido retirada da biblioteca. Citaram o fato de ser uma leitura mais divertida e dinâmica e que, com apenas um toque, a página poderia ser trocada, além da possibilidade de levá-los para qualquer lugar. Quando questionados sobre a experiência de leitura e seus pontos positivos, os educandos trouxeram considerações como:

Aluno A: "Eu não achei coisas ruins porque eu gostei bastante".

Aluno B: "Eu achei ótimo ler o livro no computador. Era fácil, pois para passar as páginas bastava apertar um botão e também podia escolher o tamanho da letra".

Aluno C: "Eu achei muito bom, pois como a maioria mexe em tecnologia foi bom, um dos melhores que eu achei foi que a gente não pegou livro da biblioteca, pois a gente sempre pega eles".

Aluno D: "Dá vontade de ler esse livro, pois ele deixa pequenas curiosidades e o livro além de ser no celular é fácil acesso".

Os discentes que baixaram obras para leitura no computador citaram como aspecto negativo apenas o fato de terem lido uma versão que não estava completa. Já aqueles que baixaram as versões para celular elencaram a fonte pequena, pois forçava os olhos e eles cansavam rapidamente, erros ortográficos e a proteção de tela que acionava. Outro fato importante mencionado foi que, por estarem quietos, eram questionados pelos pais se não estavam fazendo algo errado. $\mathrm{O}$ aluno $\mathrm{E}$ relatou: "o pai achava que estava fazendo outra coisa invés de ler". Isto é, se estivessem jogando, mas fazendo algum barulho, aos olhos dos pais, tudo estaria "correto".

Os aspectos citados podem ser percebidos em comentários como:

Aluno F: "Algo negativo é que às vezes o 'not' apagava a tela e isso era enjoado e depois de um tempo lendo as vistas começavam a doer".

Aluno G: "Ocupa bastante memória do 'not', deixa ele lento, tem que cuidar pro 'not' não cair, no meio da leitura tem que por pra carregar às vezes".

Aluno H: "Você se perde na leitura e dá um pouco de dor de cabeça".

Como pode ser percebido nos comentários, a maior parte dos problemas identificados neste tipo de leitura foram associados ao instrumento (celular, notebook ou tablet) e não ao ato de ler em si. 
Quanto à dor nos olhos e cansaço, estes fatores estão relacionados à postura do educando e a distância entre o equipamento e os olhos.

Como atividade de encerramento, os estudantes foram convidados a, eles mesmos, escolherem sua versão preferida de livro, uma vez que as atividades anteriores foram pré-estabelecidas pela professora. Assim como no questionário, os estudantes mantiveram paridade em suas escolhas, isto é, não houve uma grande diferença entre a quantidade de livros em papel em relação à versão digital. Como houve a liberdade de escolha, aqueles que já na pesquisa manifestaram o gosto pelo livro em papel retiraram-no. Enquanto que aqueles mais ligados à tecnologia aproveitaram a possibilidade de acessar a este formato de leitura. E, novamente, passada uma semana, ocorreu a última roda de conversa e registros escritos pelas turmas.

Depois de finalizadas as atividades e analisados os dados coletados, podemos afirmar que, se bem elaborada, toda atividade de leitura é válida. O livro em versão digital vem conquistando seu espaço, no entanto isso não o torna um antagonista do livro impresso, uma vez que o papel e a possibilidade de contato físico com o livro ainda são preferências de muitos estudantes.

Com base nos registros oriundos da pesquisa de campo, percebe-se que os desafios voltados ao uso da leitura digital em sala de aula são muitos, mas as possibilidades vindas dela são maiores e eficazes.

De um lado, o medo de usar a tecnologia, praticamente desconhecida, o receio de inovar e algo não ocorrer como o planejado são anseios de grande parte dos professores. A esse respeito, Teresa Colomer (2007, p. 19) destaca que, apesar de ter havido algumas tendências renovadoras favoráveis à leitura infantil de livros recreativos, isso se manteve ligado a um espaço restrito, em geral "a formação de professores continuou sendo muito deficiente do ponto de vista literário e as prioridades escolares e os métodos didáticos não tiveram grandes variações." Também surgem questões como o questionamento dos pais, os quais não conseguem acompanhar aquilo que os filhos estão fazendo no celular ou computador; o fato de o educando poder optar por uma seleção literária considerada de baixa qualidade ou até duvidosa para o bom desenvolvimento de um leitor; o uso de materiais inadequados por parte dos estudantes, inclusive a leitura de alguma obra que o docente desconhece e, para não ser questionado, este rejeita esta nova possibilidade de leitura; a promoção de atividades digitais e discussões com as quais o educador ainda não esteja bem familiarizado. Essas são pequenas barreiras que precisam ser ultrapassadas nesse contexto em que a tecnologia demanda ultrapassar os limites do papel.

De outro lado, surge o desejo de aliar novas tecnologias para despertar o interesse dos estudantes. Junto a isso, há o acesso instantâneo, os baixos custos e, acima de tudo, o crescimento do interesse pela leitura. Esses fatores, se considerados pelo educador, podem proporcionar grandes benefícios no desenvolvimento da aprendizagem dos estudantes. Além disso, facilitam o planejamento e proporcionam maior disponibilidade de tempo ao professor.

Dentro de um contexto educacional em que faltam recursos para o básico na escola, ter acesso instantâneo ao livro, além de ter uma vasta gama de obras para escolher, diminui os gastos com a aquisição de livros em papel. Entretanto, a versão digital não pode dizimar o livro em papel, pois ainda temos um grande número de estudantes que prefere o contato físico com o livro. As duas versões precisam ser aliadas e, dessa forma, atender as necessidades da escola e de seus estudantes. 
Outro fator que deve ser levado em conta é que os estudantes da atualidade não aprendem como os de algumas décadas atrás, por exemplo. Eles estão inseridos em um mundo em que tudo ocorre com muita rapidez e é este ritmo que anseiam na escola. Os métodos tradicionais de ensino, aos seus olhos, são vistos como monótonos e ultrapassados. Por que emprestar um livro velho, rasgado e, a ao ver deles, ultrapassado, se com um toque uma história moderna e em linguagem menos complicada pode estar em suas mãos? Por que não ler um livro em qualquer lugar, mas sem a "zoação" do colega?

Nossos estudantes leem muito, porém muitos não querem ser descobertos. São poucos os discentes que admitem gostar de ler perante seu grupo. O mesmo ocorre em sala de aula. Os educandos comentam aquilo que chama sua atenção. Quando uma leitura Ihes interessa eles mencionam, inclusive induzem os colegas a realizar tal leitura. Isso é referendado por Colomer quando afirma que

Compartilhar obras com outras pessoas é importante porque torna possível beneficiarse da competência de outros para construir o sentido e obter o prazer de entender mais e melhor os livros. Também porque permite experimentar a literatura em sua dimensão socializadora, fazendo com que a pessoa se sinta parte de uma comunidade de leitores com referências e cumplicidades múltiplas. (COLOMER, 2007, p. 143).

Estas são grandes possibilidades para encontrar estratégias de manter os educandos na escola e, mais do que isso, torná-los mais interessados, críticos e participativos através da leitura. Afinal, tudo que é feito com prazer desperta mais interesse.

\section{CONSIDERAÇÕES FINAIS}

A partir da pesquisa, foi possível verificar que o grande desafio de inserir a leitura digital em sala de aula ainda é o preconceito em relação ao uso de um instrumento desconhecido. Além disso, aspectos relacionados ao tamanho da fonte, luz e cansaço da visão foram vistos como negativos.

Entre as possibilidades, podem ser citadas a variedade de obras, o baixo custo e o acesso em qualquer lugar e momento. Com apenas um toque o leitor seleciona a obra que quiser e, junto com sua imaginação, embarca em maravilhosas aventuras, enfrenta monstros e inimigos para salvar a mocinha da história, diverte-se e, ao mesmo tempo, amplia sua bagagem de conhecimento.

Outro fator importante que foi constatado nesta pesquisa é que, ao contrário do que muitos pensam, os educandos estão lendo sim. E lendo muito! Porém, suas leituras muitas vezes são silenciosas, às escondidas, pois assim não estão sendo cobrados por ninguém. Além disso, eles têm autonomia para lerem o assunto que lhes interessa uma vez que o acesso à internet lhes possibilita isso.

Dessa forma, a leitura deve ser vista, tanto pelo docente quanto pelo discente, como um ato de liberdade, sem obrigações ou necessidade de uma nota e/ou avaliação da leitura. $O$ ato de ler deve ser encarado como uma atividade que cause bem-estar e prazer, pois permite que o leitor vá de um mundo ao outro sem precisar se mover. Portanto, como maior resultado deste estudo, percebeu-se que, independente do suporte - se digital ou impresso -, a leitura sempre será uma ferramenta vital à construção de sujeitos críticos, pensantes e conscientes de seu papel na sociedade. 


\section{REFERÊNCIAS}

BELO, Andre. História e livro e leitura. Belo Horizonte: Autêntica, 2007.

CHARTIER, Anne-Marie. Os modelos contraditórios da leitura entre formação e consumo. Da alfabetização à cultura de massa. Trad. Maria Helena Camara Bastos. História da Educação. ASPHE/FAE/UFPEL, Pelotas (13): 35-49, Abr. 2003. Disponível em: <http://seer.ufrgs.br/index.php/asphe/article/view/30532/pdf>. Acesso em: 16 nov. 2016.

CHARTIER, Roger. A aventura do livro: do leitor ao navegador. São Paulo: Editora UNESP/Imprensa Oficial do Estado, 1999.

COLOMER, Teresa. Andar entre livros: a leitura literária na escola. Trad. Laura Sandroni. 1. ed. São Paulo: Global, 2007.

FREIRE, Paulo. A importância do ato de ler: em três artigos que se completam. 22. ed. São Paulo: Cortez, 1988.

ROJO, Roxane (Org.). Alfabetização e letramento. 1. ed. Campinas: Mercado das Letras, 1998.

SOARES, Magda. Novas práticas de leitura e escrita: letramento na cibercultura. 1. ed. Belo Horizonte: Autêntica, 2002.

SOBRAL, Adail. Internet na escola: o que é, como se faz. 3ed. São Paulo: Loyola, 2002.

TERRA, Ernani. A produção literária e a formação de leitores em tempos de tecnologia digital. 1.ed. Curitiba: Intersaberes, 2015.

\section{APÊNDICE A - QUESTIONÁRIO}

Este questionário foi desenvolvido para fins de pesquisa acadêmica no Trabalho de Conclusão de Curso da Especialização em Ensino, Linguagens e suas Tecnologias, e tem por objetivo a análise das preferências de leitura entre os estudantes do $6^{\circ}$ ao $9^{\circ}$ ano do Ensino Fundamental desta escola.

O questionário é meramente investigativo, portanto, não há necessidade de identificar-se.

\section{Marque com $X$ suas respostas.}

\section{Idade?}

( ) 12 anos ( ) 13 anos ( ) 14 anos ( ) 15 anos ( ) 16 anos ou mais

\section{Você gosta de ler?}
( ) $\operatorname{Sim}$
( ) Não

\section{Se na questão 2 você respondeu que 'Não', por quê?}

（ ） Não gosta （ ) Não tem tempo （ ） Não possui material de leitura 

( ) Prefere assistir televisão
( ) Prefere acessar a Internet

4. Você tem acesso à Internet?

( ) Sim ( ) Não

Se você marcou SIM, marque quais são os locais de acesso:
( ) Casa ( ) Escola （ ) Casa de amigos
( ) Outros - Quais?

5. Quais são suas preferências de leitura?
( ) Livro
( ) Jornal
( ) Revista
( ) Gibi
( ) Outros. Quais?

6. Você prefere histórias de:
( ) Terror
( ) Ação
( ) Romance
( ) Suspense
( ) Comédia
( ) Outros. Quais?

7. Você já leu um livro digital?

( ) Sim ( ) Não

8. Se você respondeu SIM no item 7, marque se gostou da experiência com a leitura digital?

( ) $\operatorname{Sim}$ ( ) Não

9. Qual experiência de leitura você prefere?
( ) Livro em papel
( ) Livro digital

Por quê?

10. Com o acesso à versão digital do livro, há a possibilidade de você ler mais?
( ) Sim
( ) Não

Obrigada por sua atenção e colaboração! 